"This is a post-peer-review, pre-copyedit version of an article published in Research in Social Stratification and Mobility. The final authenticated version is available online at:

https://doi.org/10.1016/j.rssm.2020.100485".

\title{
READING WHEN THE SUN DOES NOT SHINE: THE EFFECT OF ReAding ON ChILdREN'S ACADEMIC PERFORMANCE
}

\author{
Ea Hoppe Blaabæk, \\ Department of Sociology, University of Copenhagen, Øster Farimagsgade 5, building 16 \\ 1353 København K; E-mail: ebl@ soc.ku.dk
}

\begin{abstract}
$\underline{\text { Abstract }}$
Does reading affect children's academic performance? Drawing on Scholarly Culture Theory, I hypothesize that children's reading outside of school fosters skills that enhance their academic performance. The main inferential challenge is that children who read more are likely to have other characteristics that enhance their skills, thereby complicating causal interpretation. To address this challenge, I use cross-time variation in the amount of sunshine that children are exposed to as a natural experiment that affects whether they read, but that I argue has no direct effect on their academic performance. I hypothesize that sunshine affects whether children read or not more in families with more scholarly culture (books and newspaper in the home) and higher socioeconomic status (SES) because these children have the necessary skills, means and motivations to take up reading when the sun shines less. Empirical results based on analyses of time-diary data from the Panel Study of Income Dynamics - Child Development Supplement show that (1) children who were exposed to more sunshine were less likely to read and (2) reading has a positive effect on reading, but not math, test scores.
\end{abstract}

Keywords: Reading; Academic performance; Scholarly Culture Theory; Instrumental variables

\section{Acknowledgments}

This paper has been presented at research seminars at the University of Copenhagen. I would particularly like to thank Mads Meier Jæger, Merlin Schaeffer and Richard Breen for helpful comments on previous versions of the paper. This work was supported by the Velux Foundations (Grant No. 00017000).

\section{$\underline{\text { Declaration of interests }}$}

None 


\section{Highlights}

- Does reading outside of school affect children's academic performance?

- I use amount of sunshine as a "natural experiment" that affects whether children read

- I find that when the sun shines less, children are more likely to read.

- When children read, they have higher reading, but not math, performance 


\section{INTRODUCTION}

In this paper, I ask whether reading outside of school has a positive effect on children's academic performance. The motivation for asking this question comes from a recent literature on Scholarly Culture Theory (SCT), which argues that reading is instrumental to children's educational success, because it fosters skills in children that are useful in school and improve children's academic performance (Evans, Kelley, \& Sikora, 2014; Sikora, Evans, \& Kelley, 2019).

SCT draws on research showing that being raised in a home rich in cultural capital enhances children's educational success (Georg, 2004; Jæger \& Breen, 2016; Sullivan, 2001). However, SCT argues that not all aspects of cultural capital are equally important (Evans et al., 2014; Sikora et al., 2019; Sullivan, 2007). In particular, SCT argues that reading, a key component of cultural capital, is what drives the association between cultural capital and children's educational success (Evans et al., 2014; Sikora et al., 2019; Sullivan, 2007). Unlike other aspects of cultural capital, for example familiarity with legitimate culture, a strong scholarly (or reading) culture in the home fosters skills in children that improves children's academic performance (Evans et al., 2014; Sikora et al., 2019).

SCT defines scholarly culture as "homes that abound in books and in which the way of life involves esteeming, reading, and enjoying books" and argue that "the way of life embedded in the scholarly culture develops cognitive skills, capacities, and tastes that enhance educational performance and thereby both encourage and enable children to go further in school" (Evans et al., 2014, pp. 1-2). Empirical research supports SCT as among the different indicators used to capture cultural capital reading is the one most strongly associated with educational achievement and attainment (Georg, 2004; Graaf, Graaf, \& Kraaykamp, 2000; Sullivan, 2001). 
In this paper, I focus on children's own reading and on whether children who read more have higher academic performance than those who read less. I focus on children's own reading (as opposed to, for example, being read aloud to) because, in addition to being an indicator of a coming from a home rich in scholarly culture, research suggests that reading for enjoyment improves cognitive and analytical skills (Cheung \& Andersen, 2003; Stanovich, 1993; Sullivan, 2007). I face two inferential challenges when attempting to interpret the effect of reading on academic performance as causal: reverse causality and omitted variable bias. Reverse causality implies that instead of reading having a positive effect on academic performance (as hypothesized in SCT), those who perform better are more likely to read (Stanovich, 1986; Sullivan, 2007). For example, children who enjoy reading might also enjoy doing homework and going to school. Omitted variable bias implies that rather than reading having a causal effect on academic performance, children who read more differ from children who read less with regard to unmeasured characteristics that affect academic performance. For example, children who read more might come from families that possess financial and social resources that enhance children's academic performance. If true, a positive effect of reading might indirectly pick up the effect of these unobserved characteristics.

Resolving the causal relationship between reading and academic performance is important as a comprehensive meta-study on this topic concluded that existing research is unable to disentangle correlation and causation (National Reading Panel, 2000). Empirical research has used either longitudinal data with dynamic or fixed effects models, or field experiments to identify the causal effect of reading on academic performance. Results from this research suggest that reading has a positive effect on reading and math performance (Gorard et al., 2017; Jæger \& Breen, 2016; Schneider \& Pfost, 2013; Shany \& Biemiller, 1995). Meanwhile, as the experimental literature has focused mainly on assisted reading 
programs in school (see e.g. Gorard et al., 2017) and shared book reading at home (see e.g. Barone et al., 2019), there is still little causal evidence of the effect of children reading on their own (for their own enjoyment) on their academic performance. In this paper I provide another piece to the puzzle and propose a new strategy for identifying the effect of reading on academic performance.

I use a "natural experiments" approach to shed new light on the effect of reading on the academic performance of elementary- and middle-school children (age 6-13). Inspired by Laidley and Conley (2018), I use panel data and cross-time variation in the amount of sunshine that children are exposed to on particular days as a natural experiment that affects whether they read. I combine the natural experiments approach with a fixed effects (FE) design to control for confounding from geographic variation in sunshine levels. The intuition behind the identification strategy is that children spend more time outside when there is more sunshine, which make them less likely to read. Conversely, children spend more time indoor on sedentary activities when the sun shines less, which make them more likely to read. I also argue that children from different socioeconomic backgrounds might respond in different ways to the intervention. Drawing on SCT, I hypothesize that children who come from homes with a stronger scholarly culture, and children from families with higher socioeconomic status (SES), respond more strongly to variation in sunshine because their higher baseline level of scholarly culture provides them with motivation and resources that nudge them to read when the sun shines less. I test this hypothesis by analyzing if the effect of sunshine on reading differs between children from homes rich/poor in scholarly culture and children from high- and low-SES families. 
I analyze data from the Panel Study of Income Dynamics - Child Development Supplement (PSID-CDS) ${ }^{1}$, which include detailed time-diary data for the same children measured at several points in time. For the analysis in this paper, I have two observations per child. I link the time-diary data with information on the amount of sunshine on the day of the time diary in the county in which children live. Moreover, the PSID-CDS data include information on children's academic performance (reading and math test scores), indicators of family scholarly culture (newspaper subscription, number of books the child has) and family SES. I use Instrumental Variable (IV) methods for panel data and report three main findings.

First, results show that, as expected children are less likely to read when they are exposed to more sunshine. In relation to the credibility of my identification strategy, this finding shows that amount of sunshine is a relevant IV for reading. Supplementary analyses show that the effect of sunshine on reading is similar across geographic contexts that differ with regard to weather conditions and average amounts of sunshine.

Second, when instrumenting reading with the amount of sunshine on the day covered in the time diary, I find that reading has a positive effect on children's reading (but not their math) test scores. This finding suggests that the skills acquired via reading are domain-specific. Although I measure reading (and sunshine) on a particular day, I argue that my results should not be interpreted as only capturing the effect of one day of reading. I find that reading on the day of the time diary is positively correlated with children's reading practices in general and, moreover, sunshine on one day is positively correlated with the average monthly amount of sunshine in the area in which the child lives. Another approach to

\footnotetext{
${ }^{1}$ Some of the data used in this analysis are derived from Restricted Data Files of the Panel Study of Income Dynamics, obtained under special contractual arrangements designed to protect the anonymity of respondents. These data are not available from the author. Persons interested in obtaining PSID Restricted Data Files should contact PSIDhelp@umich.edu.
} 
approximating long-term effects of time-diary measurements is to use average monthly levels of sunshine as an instrument (Frazis \& Stewart, 2012). I have used this approach in supplementary analyses and results are very similar to the main analysis (see Appendix Table A3).

Third, I study heterogeneity in the effect of the instrument. However, due to low sample sizes I do not have sufficient statistical power to strongly detect group differences when I break down the data by level of scholarly culture and SES. Therefor the results from this analysis are suggestive rather than conclusive. Though children from homes with more scholarly culture and more education seem to have a stronger response to variation in amount of sunshine, the first-stage differences between groups are not statistically significant. There is some weak statistical evidence that children from above-median income families are more likely to read when the sun shines less.

\section{THEORETICAL FRAMEWORK: SCHOLARLY CULTURE THEORY}

I now present Scholarly Culture Theory (SCT) and use this theory to motivate a link between children's reading and their academic performance. Scholarly culture encompasses the overall reading culture in the home, including parents reading aloud to their children, discussing literature at the dinner table, and providing books for their children. Building on Bourdieu's concept of cultural capital, SCT argues that scholarly culture stimulates children to read and through reading they acquire skills which lead to improved academic performance (Evans et al., 2014; Evans, Kelley, Sikora, \& Treiman, 2010; Sikora et al., 2019). SCT argues that the main explanation for an association between cultural capital and educational success, which empirical studies have identified, is not that knowledge of legitimate culture signals membership of elite groups, as some interpretations of Bourdieu 
suggest (Evans et al., 2010; Lamont \& Lareau, 1988; Weininger \& Lareau, 2003). The primary claim of SCT is that exposure to scholarly culture, in contrast to other types of legitimate culture (e.g. museum visits, knowledge of legitimate culture, playing musical instruments), fosters academic skills which lead children to have higher academic performance (Evans et al., 2014; Graaf et al., 2000; Sikora et al., 2019; Sullivan, 2001, 2007). While SCT focuses on the broader reading climate in the home, other research argues that it is particularly the reading children do themselves which has a positive effect on academic performance. Sullivan (2007) argues that reading fosters skills that enhance academic performance, for example vocabulary, expression, and decoding. Similarly, de Graaf et al (2000) argue that reading improves analytical and cognitive skills. Finally, theories in psychology argue that children's independent reading facilitates a more varied vocabulary than oral conversation, better decoding and reading fluency skills, and access to a cultural knowledge repertoire (Share, 1995; Stanovich, 1986, 1993). Based on these arguments, I propose the following hypothesis:

H1: Reading outside of school has a positive effect on children's academic performance

\subsection{Heterogeneity in the response to variation in sunshine}

SCT argues that a strong scholarly culture in the home motivates children to children to read more because parents signal that reading is enjoyable, discuss books and magazines at the dinner table, and ensure that books are available in the home. Children exposed to a strong scholarly culture mimic their parents' behaviors and pick up reading (Evans et al., 2014, 2010). Building on this idea, I argue that children from homes with more scholarly culture are more likely to read when they are exposed to less sunshine because they have a higher 
family-induced propensity to read. Following SCT, a strong scholarly culture in the home provide children with the necessary motivations, skills, and materials which make them likely to read when there is less sunshine. This argument builds on the intuition that those with a higher propensity for reading are more easily nudged into reading given less sunshine.

Building on SCT, I hypothesize that children from homes with more scholarly culture respond more to variation in sunshine than children from homes with less scholarly culture. Additionally, I hypothesize that children from high-SES families respond more to variation in sunshine. First, children from high-SES families on average come from homes with more scholarly culture (and SES is thus partially an indicator of SC; Bianchi, Cohen, Raley, \& Nomaguchi, 2004; Bianchi \& Robinson, 1997; Evans et al., 2010; Sullivan, 2007). Second, children from high-SES families have opportunity structures which make it likely that they change their behavior in response to variation in sunshine. For example, children from high-SES neighborhoods have larger homes than those from low-SES neighborhoods, which makes staying indoor when it rains a more attractive option. Moreover, they live in areas that are safer and have higher quality out-door recreational facilities, which make playing outdoor an attractive option when the sun shines (Cecil-karb \& Grogan-kaylor, 2009; Molnar, Gortmaker, Bull, \& Buka, 2004). I propose the following second hypothesis to address heterogeneity in response to sunshine:

H2 - The effect of sunshine on whether children read is higher among children from high-SES families and from homes with more scholarly culture. 


\section{RESEARCH DESIGN}

First, I run OLS (Ordinary Least Squares) regressions of reading and math performance on whether children read. However, I face two main challenges to a causal interpretation of this association between reading and academic performance: reverse causality and omitted variable bias. I address these issues by means of an instrumental variables (IV) approach and exploit variation in the amount of sunshine children were exposed to on a randomly selected day to identify variation in whether children read that is plausibly unrelated to their academic performance. Rather than identifying the Average Treatment Effect (ATE) of reading on academic performance (as would be possible with truly random assignment of reading), the natural experiment that I exploit does not automatically induce children to read more when the sun shines less. Instead, I argue that being randomly exposed to more sunshine might motivate children to read less - some children's comply with this intervention; others do not. Thus, I argue that I identify a Local Average Treatment Effect (LATE) for the children who comply with the intervention and read more when there is less sunshine and read less when there is more sunshine. As stated in hypothesis H2, high-SES children and children from homes with more scholarly culture might respond more to variation in sunshine. By combining IV and FE approaches, I am able to analyze heterogeneity in the first stage effect (which I describe below), while addressing potential bias in the second stage effect. To analyze whether high-SES children, and children from homes with more scholarly culture, react more strongly to variation in sunshine $(\mathrm{H} 2)$, I follow the approach suggested by Angrist and Pischke (2009) and compare first stage estimates for different sub-populations defined by family SES and level of scholarly culture. In this analysis, I split my sample based on two SES indicators (mother's education and family income), and two scholarly culture indicators (having a newspaper subscription and children having more than 20 books), and test whether 
the first stage estimates of the effect of sunshine on reading are significantly higher for children from homes with more SES or scholarly culture.

In the following, I describe how I address the issues of reverse causality and omitted variable bias. But first, I briefly describe the data. A more in-depth description of the data and variables follows in the next section. My primary data source is PSID-CDS, which includes repeated time diaries for children and repeated information on children's academic performance. On a randomly selected day during the school week, children filled out a time diary with information on, among other things, whether they read outside of school on that day. I combine the PSID-CDS data with meteorological data on the county average amount of sunshine $\left(\mathrm{KJ} / \mathrm{m}^{2}\right)$ on the day that children filled out the time diaries. This means that I have panel data on amount of sunshine, whether or not children read for enjoyment, and academic performance. Although I rely on information on sunshine and reading on a particular day (during the school week), these measures are good proxies for general relationships because (a) cross-time correlations in weather conditions are high (partly because of seasonal trends) ${ }^{2}$ and (b) reading on the day recorded in the time diary is positively correlated with the mothers' reports of how often children read in general (See Appendix Table A1).

I employ a fixed effect (FE) approach to address omitted variable bias. Having multiple observations of each child means I can control for time-invariant unobserved characteristics that affect whether or not children read and children's academic performance. I cluster standard errors at the family level to account for multiple siblings nested within families.

The FE approach, however, does not address reverse causality. To identify whether reading has a positive effect on children's academic performance (irrespective of any

\footnotetext{
2 The cross-time correlation in sunshine on days within a particular month and state is .78.
} 
effect of performance on reading), I need variation in children's reading that is unrelated to their academic performance. As explained above, I use exposure to sunshine as a candidate IV for the amount of active and sedentary (including reading) activities that children engage in. The IV method builds on a two-stage regression model. The first stage model isolates variation in the endogenous explanatory variable (whether children read) that arises from a source (sunshine) that is exogenous to the dependent variable (academic performance). The second stage model uses this variation to estimate the effect of reading on children's academic performance. I argue that variation in sunshine is a relevant IV for whether or not children read because research shows that sunshine increases the time children spend on sedentary activities, including reading (Bélanger, Gray-Donald, O’loughlin, Paradis, \& Hanley, 2009; Laidley \& Conley, 2018). As I have panel data, I use cross-time variation in the amount of sunshine that children were exposed to. The basic idea is that when the sun shines more, children are more likely to go outside. When the sun shines less, they stay indoors, which make it more likely that they read. Research shows that weather conditions increases the amount of time adults spend on leisure activities contra work (Connolly, 2008; Lee, Gino, \& Staats, 2014; Shi \& Skuterud, 2015), which corroborates the idea that exposure to sunshine affects the propensity to read. Moreover, one study found that respondents who reported weather as a reason for not spending more time on psychical activities, read more (Salmon, Crawford, Owen, Bauman, \& Sallis, 2003).

Fig. 1 summarizes the association between amount of sunshine and the share of children in the PSID-CDS that reported reading on the day covered in the time diary. The figure shows a negative association between the amount of sunshine $\left(\mathrm{KJ} / \mathrm{m}^{2}\right.$ coded into quintiles) and the share of children that reported reading. 


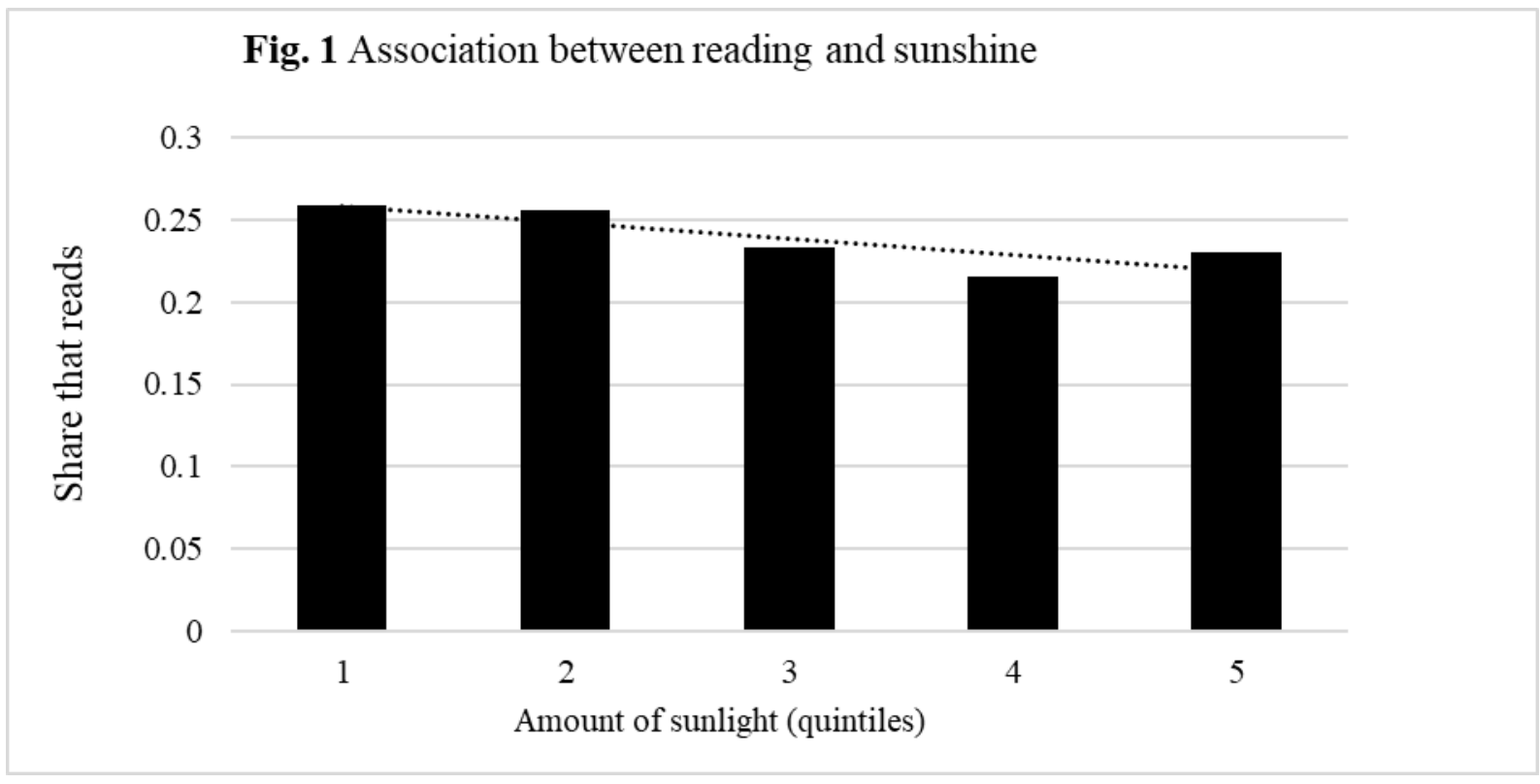

\subsection{Instrumental variable validity}

A key assumption underlying the IV approach is that sunshine only affects academic performance through its effect on whether or not children read (the instrument is valid). In this section I discuss potential threats to this assumption.

First, there is large geographic variation in the average amount of sunshine across the U.S. This fact might lead to bias if geographic place of residence is correlated with family SES, which in turn affects children's academic performance. This is likely as, for example, the southern U.S. states receive the most sunlight (particularly California, Arizona, and New Mexico) and also have below national rates of high school graduates. ${ }^{3}$ I address this potential threat by analyzing panel data in which I compare the same individuals (in the same places) over time, thereby holding constant regional differences in weather conditions.

\footnotetext{
${ }^{3}$ https://news.wjct.org/post/fact-check-floridas-solar-power-ability-limited-quite-low-sunshine (sunshine levels across states). https://nces.ed.gov/ccd/tables/ACGR_RE_and_characteristics_2016-17.asp (educational attainment across states).
} 
Second, sunshine might affect children's behaviors in other areas than reading. For example, exposure to sunshine might increase the time children are physically active, which in turn might increase their academic performance (Laidley \& Conley, 2018). In this scenario, sunshine would be positively correlated with academic performance (being more outdoor and less sedentary has a positive effect on performance) and negatively correlated with reading (children are either active or stay indoors and read). If true, this scenario means that not controlling for being active and outdoor might cause attenuation or downward bias, which means I would underestimate the effect of reading on academic performance. I address this potential threat by controlling for other activities that children also engaged in on the day covered in the time diary.

Third, sunshine might have a direct effect on children's academic performance. Research suggests that lack of exposure to sunlight is negatively related to cognitive skills because of an increased probability of depression and lower levels of vitamin D. In their literature review on the relationship between weather and depression, Laidley and Conley (2018) conclude that sunshine has only a minor effects on mood, and primarily for those who are already depressed. There is some evidence that vitamin D deficiency reduces cognitive performance (Eyles et al., 2009). I have no information on children's vitamin D levels and cannot include this as a control variable. However, this scenario would suggest a positive correlation between sunshine and academic performance (more sunshine, more vitamin D, better performance) and thus cause attenuation bias, which would make my results conservative estimates.

Fourth, sunshine might be indirectly related to academic performance because seasonal variation in sunshine might be correlated with seasonal heat-induced pollen, influenza, and children accumulating skills throughout the school year (Bensnes, 2016; Bucks et al., 2008; Fitzpatrick, Grissmer, \& Hastedt, 2011; Marcotte, 2017; Smith, 1989). I address 
this potential threat in supplementary analyses in which I control for whether children filled out the time diary during peak flu-season (February) and peak pollen season (April-June). I find no evidence that this affects my substantial results (See Appendix Table A2). Moreover, to account for any correlation between sunshine and academic performance related to the progression of the school year, I control for the number of months that have passed from September (when most schools start their academic year) until the day of the time diary. Again, this control has little bearing on my results.

\section{DATA AND VARIABLES}

I use data from the first three waves (1997, 2002 and 2007) of the Panel Study of Income Dynamics - Child Development Supplement (PSID-CDS, 2018). ${ }^{4}$ PSID is a longitudinal survey based on a nationally representative sample of individuals living in households in the U.S. The CDS follows all children of the original respondents who were 0-12 years old in 1997. The PSID-CDS data include time diaries collected in all waves (one during the school week and one during the weekend per wave). These time diaries provide a very accurate picture of children's daily activities and are one of the most accurate ways of measuring individual reading practices (Stanovich, 1993). I present the key variables in the following sections. I use data on children aged 6-13, which means that the analysis covers children in elementary and middle school. Because the survey waves are spaced approximately 5 years apart (and children have to be within the appropriate age-range in all waves), I have two observations per child. The children are 6-9 years old in the first observation and 10-13 in the

\footnotetext{
${ }^{4}$ There is also data available from a fourth wave (2014) of the PSID-CDS, which includes information on all children of the original respondents (also those born after 1997 which are not included in the 2002 and 2007 waves). I do not include data from this wave because the data cannot be matched to data on daily sunshine, which is only available until 2011.
} 
second. After listwise deletion, the analytical sample consists of 1,372 observations of 686 children. This analytical sample includes about 20 percent of the children that were originally eligible to participate in the CDS $(\mathrm{N}=3,563)$, and about 27 percent of those who between 6 and 13 years old in at least one of the survey years were $(\mathrm{N}=2,567)$. Table 1 below shows descriptive statistics for the full sample of children between 6 and 13 and for the analytical sample. A comparison of means shows that there are few systematic differences in the two samples, which suggests that the analytical sample is likely to be representative of the U.S. population of children aged 6-13.

Table 1. Descriptive statistics

\begin{tabular}{|c|c|c|c|c|c|c|}
\hline \multirow[b]{3}{*}{ Sunshine $\left(\mathrm{KJ} / \mathrm{m}^{2} / 1000\right)$ - weekday* } & \multicolumn{3}{|c|}{ Full sample (age 6-13) } & \multicolumn{3}{|c|}{$\begin{array}{l}\text { Analytical sample (age 6- } \\
\text { 13) }\end{array}$} \\
\hline & Mean & Std. dev. & $\mathrm{N}$ & Mean & Std. dev. & $\mathrm{N}$ \\
\hline & 13.41 & 6.68 & 3,295 & 11.90 & 5.90 & 1,372 \\
\hline Sunshine - weekend day* & 13.23 & 6.56 & 3,290 & 12.02 & 5.89 & 1,370 \\
\hline Sunshine - monthly average* & 13.19 & 5.34 & 3,295 & 11.86 & 4.78 & 1,372 \\
\hline Reading performance & 56.98 & 29.33 & 3,783 & 58.20 & 29.79 & 1,372 \\
\hline Math performance & 58.34 & 29.56 & 3,830 & 58.25 & 29.88 & 1,372 \\
\hline $\begin{array}{l}\text { The child has spent any amount of time } \\
\text { reading }\end{array}$ & .22 & .41 & 3,636 & .24 & .43 & 1,372 \\
\hline $\begin{array}{l}\text { Primary caregiver highest education: } \\
\text { more than High School }\end{array}$ & .49 & .50 & 3,911 & .51 & .50 & 1,312 \\
\hline $\begin{array}{l}\text { Parents have a newspaper subscription } \\
\text { in any wave of data }\end{array}$ & .52 & .50 & 3,959 & .54 & .50 & 1,372 \\
\hline Child has 20 books or more in all rounds & .50 & .50 & 4,044 & .49 & .50 & 1,372 \\
\hline $\begin{array}{l}\text { Family income above median level (av. } \\
\text { Across years) }\end{array}$ & .50 & .50 & 4,044 & .50 & .50 & 1,372 \\
\hline Family Income $(\$ 1,000)$ & 52.292 & 55.795 & 4,004 & 53.645 & 57.660 & 1,372 \\
\hline Child sex & .50 & .50 & 4,043 & .51 & .50 & 1,372 \\
\hline Child age & 10.03 & 2.31 & 4,044 & 9.92 & 2.85 & 1,372 \\
\hline Family size & 2.40 & 1.06 & 4,004 & 2.37 & 1.05 & 1,372 \\
\hline Months since September & 4.26 & 2.42 & 4,434 & 3.73 & 2.16 & 1,372 \\
\hline \multicolumn{7}{|l|}{ Hours spend on: } \\
\hline School work & 7.44 & 2.82 & 3,636 & 7.44 & 2.81 & 1,372 \\
\hline Exercise & .22 & .63 & 3,636 & .184 & .59 & 1,372 \\
\hline Outdoor activities & .10 & .46 & 3,636 & .09 & .37 & 1,372 \\
\hline TV & 1.71 & 1.58 & 3,636 & 1.69 & 1.55 & 1,372 \\
\hline Computer* & .18 & .59 & 3,636 & .24 & .65 & 1,372 \\
\hline Sedentary activities (total) & 2.13 & 1.72 & 3,636 & 2.15 & 1.72 & 1,372 \\
\hline
\end{tabular}

NOTE. $-{ }^{*}$ Difference in means between samples are statistically different at $p<.05$. 


\subsection{Dependent variables}

Academic performance. I use two subtests of the Woodcock Johnson Test of Cognitive Abilities (a) broad reading and (b) applied math performance. The broad reading indicator is composed of two further sub-tests: letter-word identification and passage comprehension. ${ }^{5}$ These tests how well children read or decode a given text and how well they infer meaning from the text ${ }^{6}$. The applied math test measures children's ability to solve word-based math problems. Both indicators of academic performance are coded into percentiles.

\subsection{Independent variables}

Reading. I use time-diary information on whether or not the child reads any type of materials (books, newspapers, magazines and other) not related to schoolwork on the day covered in the time diary. I use a binary indicator as the number of hours children report reading is most likely less strongly correlated with sunshine as the number of hours might depend on a broader range of circumstances than the choice to read. Moreover, the distribution of number of hours spent reading is highly skewed and almost binary anyway. In $76 \%$ of the observations, children do not read at all, and of those that read $81 \%$ spend between 25

\footnotetext{
${ }^{5}$ Supplementary analysis (available upon request) shows results using letter/word identification and passage comprehension independently. Results are similar.

${ }^{6}$ Duffy \& Sastry (2014: 3) describe the achievement tests in the PSID in more detail and write "The LetterWord Identification test assesses symbolic learning and reading identification skills. The Passage Comprehension test assesses reading comprehension and vocabulary, and the ability to use these two skills together in a sentence completion task."
} 
minutes and an hour reading. Table 1 shows that 24 percent of children in the sample read on the randomly selected day.

PSID-CDS also includes information on whether or not children read on a randomly selected weekend day. I do not use this information in the main analysis as the effect of sunshine on the probability than children read is likely lower in the weekend when most children have more options of what to do. For example, during weekends parents and children have the time to visit family, go to the cinema or do something similar when the sun shines less. These types of activities are less likely during the school week. Supplementary analyses (see Appendix A3) show that using the weekend time diary, children are only sensitive to more prolonged periods with less sunshine (monthly average amount), and they adjust their book reading habits more than reading magazines or newspapers. Nonetheless, the substantive results are the same if I use reading on a weekend day as my indicator of reading.

Family scholarly culture. I use two binary indicators to capture scholarly culture. The first indicator captures whether parents subscribe to a newspaper in any of the waves. Subscribing to a newspaper indicates a steady commitment to reading. The second indicator captures whether the child reported possessing 20 or more books in all waves. Again, this indicator captures a commitment to supporting reading culture in the home. This indicator is similar to home library size which Evans et al. (2010) uses to measure scholarly culture.

Family SES. I include two binary indicators of family SES capturing whether the primary caregiver (most often the mother) has obtained more than a High School degree and whether 
family income (mean across waves, price adjusted to 1997) is above or below the median income in the sample. I use binary variables to split the sample due to the low sample size.

Control variables. I include controls for several time-varying individual characteristics: family income in 1,000 \$ (price adjusted to 1997), the number of children in the household, and the age of the child in years. Furthermore, in separate models, I add controls for other types of time use, specifically hours exercising, being outdoors, doing school work, watching TV, playing computer games and total time spent on sedentary activities (e.g. watching TV, relaxing, conversations, being transported etc.).

Sunshine: My indicator of sunshine captures the average amount of sunshine in the county in which the child lives (measured in $\mathrm{KJ} / \mathrm{m}^{2} / 1000$ ) on the day covered in the time diary. The CDC (Centers for Disease Control and Prevention) collected these data and make them publically available through the online North American Land Data Assimilation System (NLDAS). Because CDC measures sunshine at the ground level it is a good proxy for general weather conditions.

\section{Results}

In the previous sections, I laid out the theoretical framework and presented two hypotheses. The first hypothesis stated that reading outside of school has a positive effect on children's academic performance. In the section below, I present the main empirical findings relating to this hypothesis. 
Model 1 and Model 4 in Table 2 show that in an OLS regression children who report reading on average have 9.5 points higher reading performance and 7.94 higher math performance (on a percentile ranked scale from 0-100) than those who do not report reading. These results are in line with my first hypothesis. However, the OLS regression does not take omitted variable bias and reverse causation into account. To tackle these issues, I use the FEIV approach, described earlier, in which I use variation in sunshine as a source of exogenous variation to identify the effect of reading on academic performance.

The bottom rows of Table 2 shows results from the first stage FE-IV regressions of the amount of sunshine on the probability that children read. All F tests are above 10, which, as a rule of thumb, suggests there is sufficient power in the first stage to credibly identify the second stage (Staiger \& Stock, 1997). As expected, the models show that the amount of sunshine has a negative effect on the probability that children read. Substantively, the probability that children read is 1.2 percentage points lower when the amount of sunshine increases by $1,000 \mathrm{KJ} / \mathrm{m}^{2}$. This estimate is equivalent to a 7 percent lower probability of reading when sunshine increases by one standard deviation.

Table 2. The effect of reading non-school related books on children's academic performance

\begin{tabular}{|c|c|c|c|c|c|c|}
\hline & Reading $\mathrm{pe}$ & erformance & $(\mathrm{WJ})$ & Math perfo & ormance $(W \mathrm{~J}$ & \\
\hline & 1 & 2 & 3 & 4 & 5 & 6 \\
\hline & OLS & FE-IV & FE-IV & OLS & FE-IV & FE-IV \\
\hline Child reads on & $9.50 * * *$ & $43.35 * *$ & $35.33 * *$ & $7.94 * * *$ & -23.93 & -21.68 \\
\hline weekday & $(1.96)$ & $(15.98)$ & $(11.84)$ & $(1.94)$ & $(13.42)$ & (11.48) \\
\hline Controls & Yes & Yes & Yes & Yes & Yes & Yes \\
\hline Time use controls & Yes & No & Yes & Yes & No & Yes \\
\hline $\mathrm{N}$ obs & 1,372 & 1,372 & 1,372 & 1,372 & 1,372 & 1,372 \\
\hline $\mathrm{N}$ groups & & 686 & 686 & & 686 & 686 \\
\hline First stage F: & & 14.93 & 24.13 & & 14.93 & 24.13 \\
\hline Daily Average & & $-.012 * * *$ & $-.013 * * *$ & & $-.012 * * *$ & $*-.013 * * *$ \\
\hline Sunshine & & $(.003)$ & $(.003)$ & & $(.003)$ & $(.003)$ \\
\hline
\end{tabular}


In Model 2 (reading performance) and Model 5 (math performance), I implement the FE-IV design, and results show that reading has a positive effect on reading, but not math, performance. In model 3 and 6 I add control variables capturing time spent on other activities than reading. If sunshine also affects the time spent on these activities, and other activities affects academic performance, these controls are necessary to obtain unbiased estimates (Deuchert \& Huber, 2017). Adding the control variables improves the F tests of the first-stage regressions considerably. While the second stage estimate shrinks some, the estimates are not statistically significantly different at $p<.05$. The final results (model 3 and 6 ) thus suggest that children who read score 35.22 points higher on the reading test than those who do not read. This is equivalent to scoring a little more than one standard deviation higher on the reading test.

The point estimates are much larger in the FE-IV model than in the OLS model, which might indicate that the OLS estimate is severely downwardly biased or that the FE-IV estimate pertains to a subpopulation for whom reading has a particularly strong effect on reading performance (LATE). It is however important to note that because of the large standard errors associated with the point estimate in the FE-IV regression, the confidence intervals for the OLS and FE-IV estimates overlap (OLS: [5.66; 13.35], FE-IV [12.12; 58.54]. Thus although the two estimates are statistically different from one-another at $p<.05$, they do not differ by much. Because of the imprecise estimate of the effect of reading on reading performance, I mainly interpret the results as showing a significant positive effect of reading on children's reading performance.

One reason why the OLS estimates might be downwardly biased, is if teachers and parents encourage lower-performing students to read more. This is likely as large-scale reading programs have focused on getting less proficient readers (from low SES families) to read more (Barone et al., 2019). While this might explain the difference between the OLS and 
FE-IV estimates, it is also likely that the FE-IV estimates are local to a particular part of the population (LATE). Studies argue that so-called "Matthew effects" lead skilled readers to learn more from reading than less skilled readers because they have a better prior understanding of words, syntax and context (Mol \& Bus 2011). The theoretical expectation (hypothesis 2) is that children from families with more scholarly culture and higher SES respond more to the intervention. If this is true, and these children have higher academic performance, this could suggest that I identify a LATE effect that might be higher that than an average effect across the entire population (Average Treatment Effect; ATE). In the following analysis, I test whether, as expected in hypothesis 2, the analysis indicates that the result are a LATE effect for particularly children from families with more scholarly culture and/or higher SES. I note that because of insufficient power, I do not test whether the second stage effect of reading on academic performance differ between groups.

Results from Model 6 show that reading does not affect children's math performance. A null effect of reading on math performance is not what I expected based on previous literature, but as it is in line with theories from psychology it is not entirely improbable. These theories suggest that reading primarily affects decoding skills and that more general cognitive skills (e.g., analytical or processing skills) are more likely to enhance reading than being affected by it (Share, 1995; Stanovich, Cunningham, \& Feeman, 1984). In alternative specifications, for example when using average monthly sunshine as an instrument (to capture long-term exposure to sunshine), the negative effect of reading on math performance reaches statistical significance at $p<.05$. This analysis suggests that although there is a large degree of uncertainty in the result, there is some (weak) evidence that reading has a negative effect on children's math performance. This is the opposite of what was expected in hypothesis $H 1$. A negative effect on math performance could reflect that when the sun shines less and children read more, they also engage in more sedentary activities 
(which has a negative effect on math skills; Laidley and Conley, 2018) or they engage in fewer activities which might have improved their math skills (e.g., coding, doing puzzles, playing musical instruments, etc.). The counterfactual is thus not only that children read vs. do not read, but that they spend time on reading rather than on other activities. To the extent that the negative effect of math is real, it most likely reflects a displacement of other activities.

My empirical results show that the effect of reading is domain-specific and only pertains to reading performance. Put differently, reading primarily affects academic performance in domains related to reading such as decoding and reading comprehension, but does not affect general domains of academic performance captured by the math test.

\subsection{Heterogeneity in the effect of sunshine on reading}

I hypothesized that children from homes with more scholarly culture and high SES respond more to the variation in sunshine because they already possess the necessary resources, skills, and motivations to take up reading when there is less sunshine. I now test this hypothesis by analyzing differences in first stage results for different sub-populations. Specifically, I compare (a) children whose parents (do not) have a newspaper subscription, (b) children who (do not) have 20 or more books in all survey rounds, (c) children whose mothers have (less than) a high school degree, and (d) children whose families have above (below) median family income. Table 3 presents results from the first and second stage results for FE-IV regressions on the split samples, as well as p-values from a z-test of whether the difference in first stage effects between the comparison groups are statistically significant. 
Table 3. First and Second Stage results on reading performance for sub-groups

\begin{tabular}{|c|c|c|c|c|c|c|}
\hline & & $\begin{array}{l}\text { Share of } \\
\text { sample }\end{array}$ & First stage & F test & $\begin{array}{l}\text { Second } \\
\text { stage }\end{array}$ & $\begin{array}{l}Z \text { test (p- } \\
\text { value) }\end{array}$ \\
\hline \multirow[t]{4}{*}{$\begin{array}{l}\text { Family scholarly } \\
\text { culture }\end{array}$} & $\begin{array}{l}\text { No newspaper } \\
\text { subscription }\end{array}$ & .46 & $\begin{array}{l}-.011 * * \\
(.004)\end{array}$ & 6.70 & $\begin{array}{c}66.76 \\
(32.86)\end{array}$ & .549 \\
\hline & $\begin{array}{l}\text { Newspaper } \\
\text { subscription }\end{array}$ & .54 & $\begin{array}{l}-.014 * * * \\
(.003)\end{array}$ & 18.45 & $\begin{array}{c}20.04 \\
(11.23)\end{array}$ & \\
\hline & $\begin{array}{l}\text { Fewer than } 20 \\
\text { books }\end{array}$ & .51 & $\begin{array}{l}-.009 * * \\
(.004)\end{array}$ & 6.45 & $\begin{array}{c}48.94 \\
(27.72)\end{array}$ & .112 \\
\hline & $\begin{array}{l}20 \text { books or } \\
\text { more }\end{array}$ & .49 & $\begin{array}{l}-.018 * * * \\
(.004)\end{array}$ & 21.13 & $\begin{array}{l}24.83 * * \\
(9.59)\end{array}$ & \\
\hline \multirow[t]{2}{*}{ Mother's education } & $\begin{array}{l}\text { High School } \\
\text { or less }\end{array}$ & .49 & $\begin{array}{l}-.009^{*} \\
(.004)\end{array}$ & 4.56 & $\begin{array}{c}52.29 \\
(31.50)\end{array}$ & .112 \\
\hline & $\begin{array}{l}\text { More than } \\
\text { High School }\end{array}$ & .51 & $\begin{array}{l}-.018 * * * \\
(.004)\end{array}$ & 21.32 & $\begin{array}{c}21.59 * \\
(10.79)\end{array}$ & \\
\hline \multirow[t]{2}{*}{ Family income } & Below median & .50 & $\begin{array}{l}-.008^{*} \\
(.004)\end{array}$ & 4.20 & $\begin{array}{c}52.63 \\
(33.47)\end{array}$ & .052 \\
\hline & Above median & .50 & $\begin{array}{l}-.019 * * \\
(.004)\end{array}$ & 24.42 & $\begin{array}{l}26.14 * \\
(11.11)\end{array}$ & \\
\hline
\end{tabular}

NOTE. - Two-tailed tests. $* P<.05$, $* * P<.01, * * * P<.001$. Controls: Child age, months since school started, family income, family size. Time use controls (hours): exercising, being outdoors, in school or doing homework, watching TV, using a computer and total sedentary activities.

Based on the results presented in table 3, I find limited evidence that children from high-SES backgrounds and those rich in scholarly culture respond more to variation in sunshine. Specifically, the difference in the first stage estimates with regard to newspaper subscription, books, and parents' education are not statistically significant. ${ }^{7}$ However, the insignificant difference (z) tests might be due to insufficient power. With more power, the differences there are between families might prove statistically significant. Despite the lack of power, I find that the first stage difference between children from families with an income above or below the median is weakly statistically significant, which suggest that compliers might be more likely to come from higher income families and that results thus could be local to children from higher income families (LATE). I discuss the interpretation of the results from this analysis more in the discussion section below.

\footnotetext{
${ }^{7}$ Differences in second stage effects of reading on reading performance are also not statistically significant. I do not have sufficient power to detect second stage differences.
} 


\section{Robustness CheCKS}

In this section I address the robustness of my findings. A potential concern regarding the use of sunshine as an instrument is whether it mainly affects children that already have a high reading performance. It might be that children who read well are more likely to read when there is less sunshine (Matthew effect: those who are skilled practice more (Stanovich, 1986)). This situation would imply that the instrument is not exogenous to children's academic performance. To assess this potential problem, I have run models separately for children who were at different levels of academic performance when they were first interviewed (see Appendix A4). The first stage results concerning the effect of sunshine on reading are similar in these models which suggests children who start out at a higher performance level do not respond more to the instrument. Further, tests show that boys and girls react in similar fashion to variation in sunshine.

Another potential issue relates to whether $1,000 \mathrm{KJ} / \mathrm{M}^{2}$ change in sunshine has the same effect across all geographical contexts. For example, it is likely that a child living in a very sunny region needs are larger sunshine "shock" - in relative terms - to change their reading behavior than a child living in a less sunny region. I have addressed this issue in several ways (see Appendix A2). First, I have run models separately for federal states that have above/below the median amount of sunshine. Second, I have standardized the sunshine variable within each state and year so that a change in sunshine is measured relative to the average level within that state and year. Moreover, I have run models where I use the difference to the average amount of sun within the state*year as the instrument. Third, I have added state dummies to the regressions to capture any cross-state heterogeneity in the first 
stage effect. Overall the results from these models suggest that the effect of sunshine is uniform across geographic contexts.

As a final robustness check, Appendix A5 shows results from a multi-model analysis where I run models for all possible combinations of a range of different model specification choices (1,536 models in total) (Young \& Holsteen, 2017). I vary the following specifications. Sunshine measures: $\mathrm{KJ} / \mathrm{m}^{2}$ on day of time diary, monthly average $\mathrm{KJ} / \mathrm{m}^{2}$, and sunshine standardized within state and year. Binary and continuous (hours) indicator of reading. Including the following control variables (or not): months since school start, hours spend on: school and homework, exercise, being outdoor, watching TV, using a computer, and being passive. The figure in appendix A5 shows the number of models at a given p-value and whether the estimated effect of reading on academic performance is positive or negative. In $96 \%$ of the models on reading performance, the effect is positive and significant (in the other $4 \%$ of the models, the estimate is positive and the $p$-value is below .061). Thus the result is highly robust to model specification (Young \& Holsteen, 2017:14 define $95 \%$ as the threshold for "strong robustness"). In contrast, the effect of math is negative in all model, but only significant at $\mathrm{p}<.05$ in $25 \%$ of the models. The majority of the evidence thus suggests that the negative effect of reading on math performance is not statistically significant.

\section{DISCUSSION}

In this paper, I test whether one aspect of scholarly culture: children's reading outside of school, affects their academic performance. I face two challenges to a causal interpretation of the association between children's reading and their academic performance: omitted variable bias and reverse causality. To deal with these issues, I use within-individual variation in exposure to sunshine as a source of plausibly exogenous variation in whether children read. 
I use time-diary data from the PSID-CDS and present three main findings. First, after controlling for individual fixed effects, I find a positive effect of sunshine on the probability that children read. Second, reading has a positive effect on reading, but not on math performance. Third, I find limited evidence of heterogeneity in the effect of sunshine on whether children read between families with more and less scholarly culture and SES.

The second finding of a positive effect of reading on reading performance contributes to current research on the causal effect of reading on children's academic performance. In 2000 the National Reading Panel reviewed literature testing the effect of children reading by themselves on their reading skills. They concluded that at present there was not enough empirical evidence, of a sufficiently high standard, to conclude whether children's independent reading improves their reading skills (National Reading Panel 2000). Similarly, Mol \& Bus (2011) criticize the literature for being primarily correlational. Previous causal evidence of the effect of reading on reading performance either use experimental or panel data methods. Experimental studies have focused primarily on (a) reading in a school context, e.g. assisted reading interventions or (b) shared book reading (Barone et al., 2019; Gorard et al., 2017; Mol \& Bus, 2011; Shany \& Biemiller, 1995). Moreover, as these experimental studies tend to be based on small ad-hoc samples, the external validity of the findings from this research is unclear (Barone et al., 2019). Though panel data methods control for bias from unobserved time-invariant factors and are usually based on large-scale representative samples, they cannot control for bias from unobserved time-variant factors (such as evolving preferences, abilities, investments etc.) (Jæger \& Breen, 2016; Schneider \& Pfost, 2013). This study adds to the literature by providing a stronger empirical design compared to studies using panel data methods and by providing evidence of the effects of children reading by themselves (rather than reading assisted by parents or teachers). 
With regard to the analysis of heterogeneity, I only find that children from higher income families have a (weekly) significantly stronger response to sunshine. While this finding supports the theoretical expectation that children from more advantaged families (higher SES) respond more to the intervention, the results should be interpreted with some care. On one hand, the result could indicate that the estimated effects are primarily local to children from more financially well-off families (LATE) - who may have a stronger treatment effect than that in the average population, given that they likely have a higher initial skill level (Matthew effect). On the other, I find no significant first stage differences between children of more or less educated parents or children with more and less scholarly culture. This indicates that overall there is only limited evidence in favor of hypothesis 2 . However, although the differences in the first stage effects between families with more and less scholarly culture and more/less education are not statistically significant, the direction of all the tests indicate that children from families with more scholarly culture and SES respond more to the instrument (thus weakly suggesting that results are a LATE for more advantaged children). The lack of significance of the first stage differences could be due to (a) there is no heterogeneity in the effect, (b) lack of power in the instrument and (c) a binary split is too crude to capture the relevant type of heterogeneity. Ultimately, given the low power and the inconsistent evidence, the results of this part of the analysis are rather suggestive and inconclusive. More research is needed to ascertain how children's reading behavior depends on family scholarly culture and SES.

The second result supports the key argument in SCT: that reading has a positive effect on children's academic performance. My results thus add to a growing literature on the particular importance of children's reading practices to their educational performance and success (Breinholt \& Jæger, 2020; Georg, 2004; Jæger \& Breen, 2016; Mol \& Bus, 2011; Sullivan, 2001, 2007). It should be noted that I only test one aspect of SCT and not the whole 
theory. Though robust empirical evidence substantiating this essential claim of SCT is an important step towards testing the general theory, the tests presented in this paper do not rule out that scholarly culture affect children's academic performance (more or less) through other channels. Promising avenues for future research are to analyze the extent to which children's reading practices depends on the broader scholarly culture in the home and whether scholarly culture affects children's educational success through other channels, e.g., through increasing their non-cognitive skills.

The results presented in this paper show that reading has a positive effect on reading, but not on math, performance. These results indicates that reading has a positive effect on skills that particularly affect reading performance, but are not as clearly related to performance on the math tests. This type of domain-specific effect is not fully in line with previous research which finds reading to also affect math test scores and general cognitive performance tests (Breinholt \& Jæger, 2020; Jæger \& Breen, 2016; Kalb \& van Ours, 2013; Sullivan, 2001). However, the result is consistent with theories in psychology which suggest that when children read on their own they primarily improve decoding skills, and that general cognitive skills (e.g. analytic or processing skills) are more likely to facilitate reading (Share, 1995; Stanovich et al., 1984). An explanation for the discrepancy to previous sociological research could be that the results reflect different counterfactuals. Given that I use time-diary data, I potentially estimate the effect of reading compared to doing math-improving activities (reading displaces other activities) rather than simply estimating the effect of reading compared to not reading. The discrepancy could also reflect effects in different populations (different LATE groups). One approach to studying whether the potentially negative effect of reading on math performance is a result of displacement of other activities is to compare afterschool or summer school programs with different curriculum. Are there negative effects on math performance of programs which particularly emphasize reading compared to broader 
programs which include for example both reading, math and extracurricular activities such as playing instruments? Identifying cases that would allow such a comparison is an interesting path for further research.

A potential limitation in this paper relates to whether reading on one day (the day of the time diary) is a good proxy for children's general reading practices (which is what SCT is about). The only indicator of children's long-term reading behavior in the PSID-CDS data is the mother's response to how often the child reads (daily, weekly, monthly, yearly, never), which the mother has answered for children aged 10 and above. I find that reading on the day of the time diary is positively correlated with reading daily and negatively correlated with less frequent reading. This suggests that reading on the day of the time diary is a good indicator of very frequent reading practices (see Appendix Table A1). Another approach is to use average sunshine over longer time periods as an instrument for whether children read on the day of the time diary. In their paper on how to infer long-term treatment effects from single day time diaries, Frazis and Stewart (2012) suggest instrumenting time-use on a particular day with instruments that affect long-term time-use - such as average weather conditions across longer periods of time. In Appendix Table A3 I use this approach and show that results are similar when I instrument reading with the monthly average amount of sunshine. This suggests that though results reflect the effect of a relatively short-term shock to reading, they should not be interpreted as a positive effect of children reading on just one day in their lives.

Looking beyond research, the results presented in this paper also lends (further) credence to the popular recommendation that school children should read frequently outside of school. Large organizations such as the National Campaign for Grade-Level Reading ${ }^{8}$ in

\footnotetext{
${ }^{8}$ http://readdbq.org/2014/11/19/read-20-minutes-day/ (The Dubuque Campaign for for Grade-Level Reading)
} 
the US and the National Literacy Trust ${ }^{9}$ in the UK recommend that children read daily for about 20 minutes and view this as a way to reduce a (socioeconomic) gap in reading between poor and proficient readers. Previous research shows that high-SES children read more than low-SES children, and this paper shows that reading has a positive effect on children's reading performance (Bianchi \& Robinson, 1997; Gershenson, 2013). Thus, if targeted interventions can get low-SES children to read more, this might help reduce inequality in children's reading performance.

\section{REFERENCES}

Angrist, J., \& Pischke, J.-S. (2009). Mostly Harmless Econometrics. An Empiricist's Companion. Princeton and Oxford: Princeton University Press.

Barone, C., Chambouleyron, E., Vonnak, R., \& Assirelli, G. (2019). Shared Book Reading Interventions and Children's Skills: a Meta-Analysis of Randomised Controlled Trials. Sciences Po LIEPP Working Paper $n^{\circ} 98$.

Bélanger, M., Gray-Donald, K., O’loughlin, J., Paradis, G., \& Hanley, J. (2009). Influence of Weather Conditions and Season on Physical Activity in Adolescents. Annals of Epidemiology, 19(3), 180-186. https://doi.org/10.1016/j.annepidem.2008.12.008

Bensnes, S. S. (2016). You sneeze, you lose: The impact of pollen exposure on cognitive performance during high-stakes high school exams. Journal of Health Economics, 49, 1-13. https://doi.org/10.1016/j.jhealeco.2016.05.005

Bianchi, S. M., Cohen, P. N., Raley, S., \& Nomaguchi, K. (2004). Inequality in Parental Investment in Child-Rearing: Expenditures, Time, and Health. In K. Neckerman (Ed.), Social Inequality (pp. 189-219). Russel Sage Foundation. https://doi.org/10.1007/SpringerReference_76056

Bianchi, S. M., \& Robinson, J. (1997). What Did You Do Today? Children's Use of Time, Family Composition and the Acquisition of Social Capital. Journal of Marriage and Family, 59(2), 332-344.

Breinholt, A., \& Jæger, M. (2020). "How does cultural capital affect educational performance: Signals or skills?” British Journal of Sociology, 71:28-46

Bucks, R. S., Gidron, Y., Harris, P., Teeling, J., Wesnes, K. A., \& Perry, V. H. (2008). Selective effects of upper respiratory tract infection on cognition, mood and emotion processing : A prospective study. Brain, Behavior and Immunity, 22, 399-407. https://doi.org/10.1016/j.bbi.2007.09.005

\footnotetext{
${ }^{9}$ http://literacytrust.org.uk/policy-and-campaigns/read-on-get-on/ (Read on. Get on.)
} 
Cecil-karb, R., \& Grogan-kaylor, A. (2009). Childhood Body Mass Index in Community Context: Neighborhood Safety, Television Viewing, and Growth Trajectories of BMI. Health and Social Work, 34(3), 169-177.

Cheung, S. Y., \& Andersen, R. (2003). Time to Read: Family Resources and Educational Outcomes in Britain. Journal of Comparative Family Studies, 34(3), 413-433.

Connolly, M. (2008). Here comes the rain again: Weather and the intertemporal substitution of leisure. Journal of Labor Economics, 26(1), 73-100. https://doi.org/10.1086/522067

Deuchert, E., \& Huber, M. (2017). A Cautionary Tale About Control Variables in IV Estimation. Oxford Bulletin of Economics and Statistics, 79(3), 411-425. https://doi.org/10.1111/obes.12177

Duffy, D. \& Sastry, N. (2014). Achievement Tests in the Panel Study of Income Dynamics Child Development Supplement. PSID Technical Series Paper \#14-02.

Evans, M. D. R., Kelley, J., \& Sikora, J. (2014). Scholarly Culture and Academic Performance in 42 Nations. Social Forces, 92(4), 1573-1605. https://doi.org/10.1093/sf/sou030

Evans, M. D. R., Kelley, J., Sikora, J., \& Treiman, D. J. (2010). Family scholarly culture and educational success: Books and schooling in 27 nations. Research in Social Stratification and Mobility, 28(2), 171-197. https://doi.org/10.1016/j.rssm.2010.01.002

Eyles, D. W., Feron, F., Cui, X., Kesby, J. P., Harms, L. H., Ko, P., ... Burne, T. H. J. (2009). Developmental vitamin D deficiency causes abnormal brain development. Psychoneuroendocrinology, 34S, S247-S257. https://doi.org/10.1016/j.psyneuen.2009.04.015

Fitzpatrick, M. D., Grissmer, D., \& Hastedt, S. (2011). What a Difference a Day Makes: Estimating Daily Learning Gains During Kindergarten and First Grade Using a Natural Experiment. Economics of Education Review, 30(2), 269-279.

Frazis, H., \& Stewart, J. (2012). How to Think about Time-Use Data: What Inferences Can We Make about Long- and Short-Run Time Use from Time Diaries? Annals of Economics and Statistics, (105/106), 231. https://doi.org/10.2307/23646463

Georg, W. (2004). Cultural capital and social inequality in the life course. European Sociological Review, 20(4), 333-344. https://doi.org/10.1093/esr/jch028

Gershenson, S. (2013). Do Summer Time-Use Gaps Vary by Socioeconomic Status? American Educational Research Journal, 50(6), 1219-1248. https://doi.org/10.3102/0002831213502516

Gorard, S., Siddiqui, N., \& See, B. H. (2017). What works and what fails? Evidence from seven popular literacy 'catch-up' schemes for the transition to secondary school in England. Research Papers in Education, 32(5), 626-648. https://doi.org/10.1080/02671522.2016.1225811

Graaf, N. D. De, Graaf, P. M. De, \& Kraaykamp, G. (2000). Parental Cultural Capital and Educational Attainment in the Netherlands: A Refinement of the Cultural Capital Perspective. Sociology of Education, 73(2), 92. https://doi.org/10.2307/2673239

Jæger, M. M., \& Breen, R. (2016). A Dynamic Model of Cultural Reproduction. American Journal of Sociology, 121(4), 1079-1115. https://doi.org/10.2139/ssrn.2208961 
Kalb, G., \& van Ours, J. c. (2013). Reading to Young Children : A Head-Start in Life. IZA Discussion Paper Series, (7416).

Laidley, T., \& Conley, D. (2018). The Effects of Active and Passive Leisure on Cognition in Children: Evidence from Exogenous Variation in Weather. Social Forces, 97(September), 129-156. https://doi.org/10.1093/sf/soy020

Lamont, M., \& Lareau, A. (1988). Cultural Capital : Allusions , Gaps and Glissandos in Recent Theoretical Developments. Sociological Theory, 6(2), 153-168.

Lee, J. J., Gino, F., \& Staats, B. R. (2014). Rainmakers: Why Bad Weather Means Good Productivity. Journal of Applied Psychology, 99, 504-513.

Marcotte, D. E. (2017). Something in the air? Air quality and children's educational outcomes. Economics of Education Review, 56, 141-151. https://doi.org/10.1016/j.econedurev.2016.12.003

Mol, S. E., \& Bus, A. G. (2011). To Read or Not to Read: A Meta-Analysis of Print Exposure From Infancy to Early Adulthood. Psychological Bulletin, 137(2), 267-296. https://doi.org/10.1037/a0021890

Molnar, B. E., Gortmaker, S. L., Bull, F. C., \& Buka, S. L. (2004). Unsafe to Play ? Neighborhood Disorder and Lack Among Urban Children and Adolescents. American Journal of Health Promotion, 18(5), 378-387.

National Reading Panel. (2000) Report of the National Reading Panel--Teaching Children to Read: An Evidence-Based Assessment of the Scientific Research Literature on Reading and Its Implications for Reading Instruction. Washington, D.C.: National Institute of Child Health and Human Development.

PSID-CDS. (2018). Panel Study of Income Dynamics, restricted use data. Produced and distributed by the Survey Research Center, Institute for Social Research. University of Michigan, Ann Arbor, MI.

Salmon, J., Crawford, D., Owen, N., Bauman, A., \& Sallis, J. F. (2003). Physical activity and sedentary behavior: A population-based study of barriers, enjoyment, and preference. Health Psychology, 22(2), 178-188. https://doi.org/10.1037/0278-6133.22.2.178

Schneider, T., \& Pfost, M. (2013). Social and Immigration-Specific Differences in the Development of Reading Comprehension: A Longitudinal Analysis of Primary School Students in Germany. In The Development of Reading Literacy From Early Childhood to Adolescence. Empirical Findings from the Bamberg BiKS Longitudinal Studies (pp. 151-188). Bamberg: Univeristy of Bamberg Press.

Shany, M. T., \& Biemiller, A. (1995). Assisted Reading Practice Effects on Performance for poor readers in Grades 3 and 4. Reading Research Quarterly, 30(3), 382-395.

Share, D. L. (1995). Phonological recoding and self-teaching. Cognition, 55(2), 151-218. https://doi.org/10.1016/j.psep.2007.11.003

Shi, J., \& Skuterud, M. (2015). Gone fishing! Reported sickness absenteeism and the weather. Economic Inquiry, 53(1), 388-405. https://doi.org/10.1111/ecin.12109

Sikora, J., Evans, M. D. R., \& Kelley, J. (2019). Scholarly culture : How books in adolescence enhance adult literacy, numeracy and technology skills in 31 societies. Social Science Research, 77, 1-15. https://doi.org/10.1016/j.ssresearch.2018.10.003 
Smith, A. (1989). A Review of the Effects of Colds and Influenza on Human Performance. Occupational Medicine, 39(2), 65-68.

Staiger, D., \& Stock, J. H. (1997). Instrumental Variables Regression with Weak Instruments Author. Econometrica, 65(3), 557-586.

Stanovich, K. E. (1986). Matthew Effects in Reading: Some Consequences of Individual Differences in the Acquisition of Literacy. Reading Research Quarterly, 21(4), 360407. https://doi.org/10.1598/RRQ.21.4.1

Stanovich, K. E. (1993). Does reading make you smarter. In H. W. Reese (Ed.), Advances in Child Development and Behavior (pp. 135-180). San Diego: Academic Pres, Harcourt Brace Jovanovich Publishers.

Stanovich, K. E., Cunningham, A. E., \& Feeman, D. J. (1984). Intelligence, Cognitive Skills , and Early Reading Progress. Reading Research Quarterly, 19(3), 278-303.

Sullivan, A. (2001). Cultural Capital and Educational Attainment. Sociology, 35(4), 893-912.

Sullivan, A. (2007). Cultural capital, cultural knowledge and ability. Sociological Research Online, 12(6), 1-14. https://doi.org/10.5153/sro.1596

Weininger, E. B., \& Lareau, A. (2003). Translating Bourdieu into the American context: The question of social class and family-school relations. Poetics, 31(5-6), 375-402. https://doi.org/10.1016/S0304-422X(03)00034-2

Young, C., \& Holsteen, K. (2017). Model Uncertainty and Robustness: A Computational Framework for Multimodel Analysis. Sociological Methods and Research (Vol. 46). https://doi.org/10.1177/0049124115610347 


\section{APPENDIXES}

Appendix Table A1. Polychoric correlations between reading on the day of the time diary and long-term reading practices.

Child reads daily

Child reads several times a week

The child reads on the day of the time diary

Child reads several times a month

Binary indicator

Child reads several times a year

.39

Time-use (hours)

Child never reads

NOTE. - Mothers have only reported children's reading practices for children age 10+. $\mathrm{N}: 685$. 
Appendix Table A2. Robustness Checks: Seasonal and geographic variation

\begin{tabular}{|c|c|c|c|c|c|c|c|c|}
\hline & Flu ar & nd allergy s & season & & $\mathrm{Gec}$ & ggraphic var & iation & \\
\hline & 1 & 2 & 3 & 4 & 5 & 6 & 7 & 8 \\
\hline Child reads & $\begin{array}{l}33.85^{* *} \\
(12.80) \\
\end{array}$ & $\begin{array}{l}45.88^{*} \\
(21.60) \\
\end{array}$ & $\begin{array}{l}46.61 * \\
(21.70) \\
\end{array}$ & $\begin{array}{l}22.21^{*} \\
(11.04) \\
\end{array}$ & $\begin{array}{c}63.81 \\
(35.56) \\
\end{array}$ & $\begin{array}{l}36.04 * * \\
(13.73) \\
\end{array}$ & $\begin{array}{l}31.26^{* * *} \\
(12.49)\end{array}$ & $\begin{array}{l}35.16^{* *} \\
(11.84)\end{array}$ \\
\hline Controls & Yes & Yes & Yes & Yes & Yes & Yes & Yes & Yes \\
\hline Time-use controls & Yes & Yes & Yes & Yes & Yes & Yes & Yes & Yes \\
\hline $\mathrm{N}$ obs & 1,372 & 1,372 & 1,372 & 688 & 646 & 1,368 & 1,368 & 1,372 \\
\hline $\mathrm{N}$ groups & 686 & 686 & 686 & 269 & 245 & 684 & 684 & 686 \\
\hline Additional controls: & & & & & & & & \\
\hline Peak Flu month & $\mathrm{X}$ & & $\mathrm{X}$ & & & & & \\
\hline Peak pollen month & & $\mathrm{X}$ & $\mathrm{X}$ & & & & & \\
\hline State dummy & & & & & & & & $\mathrm{X}$ \\
\hline Sample: & & & & & & & & \\
\hline $\begin{array}{l}\text { State sunshine level below national } \\
\text { median }\end{array}$ & & & & $X$ & & & & \\
\hline $\begin{array}{l}\text { State sunshine level above national } \\
\text { median }\end{array}$ & & & & & $\mathrm{X}$ & & & \\
\hline First stage F: & 19.86 & 9.59 & 9.74 & 21.16 & 5.11 & 18.47 & 21.45 & 23.37 \\
\hline Daily average Sunshine & $\begin{array}{l}-.013 * * * \\
(.003)\end{array}$ & $\begin{array}{l}-.010 * * \\
(.003)\end{array}$ & $\begin{array}{l}-.010 * * \\
(.003)\end{array}$ & $\begin{array}{l}-.017 * * * \\
(.004)\end{array}$ & $\begin{array}{l}-.009 * \\
(.004)\end{array}$ & & & $\begin{array}{l}-.013 * * * \\
(.003)\end{array}$ \\
\hline $\begin{array}{l}\text { Sunshine standardized within } \\
\text { state*year }\end{array}$ & & & & & & $\begin{array}{r}-.070^{* *} \\
(.016)\end{array}$ & & \\
\hline $\begin{array}{l}\text { Sunshine on day of time diary as } \\
\text { deviation from state*year average }\end{array}$ & & & & & & & $\begin{array}{l}-.011^{* * *} \\
(.002)\end{array}$ & \\
\hline
\end{tabular}


Appendix Table A3. Weekend Reading and weekly/monthly average amount of sunshine.

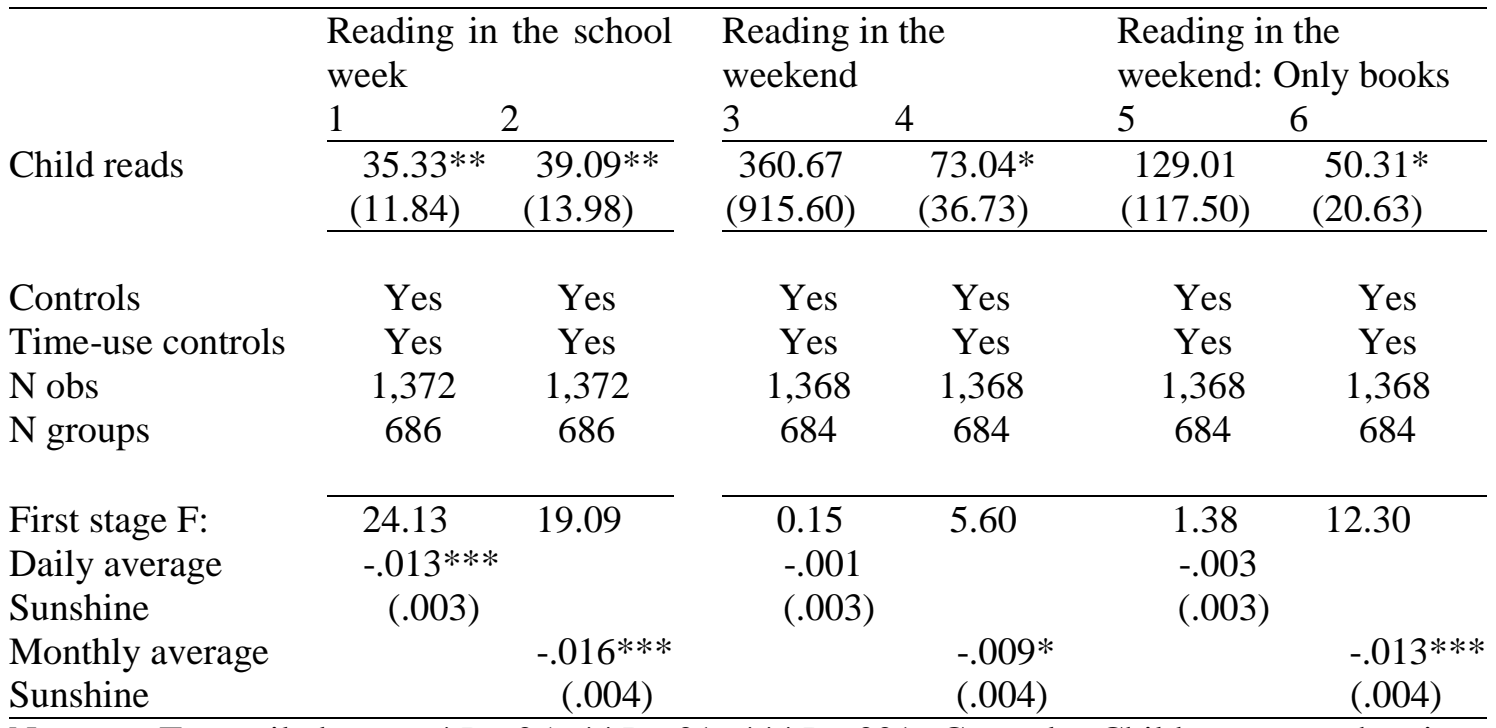

NOTE. - Two-tailed tests. $* P<.05, * * P<.01$, $* * * P<.001$. Controls: Child age, months since school started, family income, family size. Time use controls (hours): exercising, being outdoors, in school or doing homework, watching TV, using a computer and total sedentary activities. 
Appendix Table A4. Robustness Checks: Sample differences

\begin{tabular}{|c|c|c|c|c|}
\hline \multirow{3}{*}{$\begin{array}{l}\text { Above/below Median } \\
\text { Child reads }\end{array}$} & \multicolumn{2}{|c|}{ Initial skill level } & \multicolumn{2}{|c|}{ Gender } \\
\hline & Below & Above & Female & Male \\
\hline & $\begin{array}{c}44.37 \\
(23.76) \\
\end{array}$ & $\begin{array}{c}18.83 \\
(10.11) \\
\end{array}$ & $\begin{array}{l}21.35 \\
(12.07) \\
\end{array}$ & $\begin{array}{l}\text { 49.27* } \\
(21.90)\end{array}$ \\
\hline Controls & Yes & Yes & Yes & Yes \\
\hline N obs & 754 & 618 & 564 & 808 \\
\hline $\mathrm{N}$ groups & 377 & 259 & 282 & 404 \\
\hline $\begin{array}{l}\text { First stage F: } \\
\text { Daily average Sunshine }\end{array}$ & $\begin{array}{l}7.71 \\
-.010 * * \\
(.004)\end{array}$ & $\begin{array}{l}18.14 \\
-.016 * * * \\
(.004)\end{array}$ & $\begin{array}{l}18.80 \\
-.016^{* * * *} \\
(.004)\end{array}$ & $\begin{array}{l}8.43 \\
-.011 * * * \\
(.004)\end{array}$ \\
\hline
\end{tabular}

NOTE. - Two-tailed tests. $* P<.05$, $* * P<.01$, $* * * P<.001$. Controls: Child age, months since school started, family income, family size. Time use controls (hours): exercising, being outdoors, in school or doing homework, watching TV, using a computer and total sedentary activities.

Appendix A5. P-values for positive and negative effect estimates from multi-model analysis.

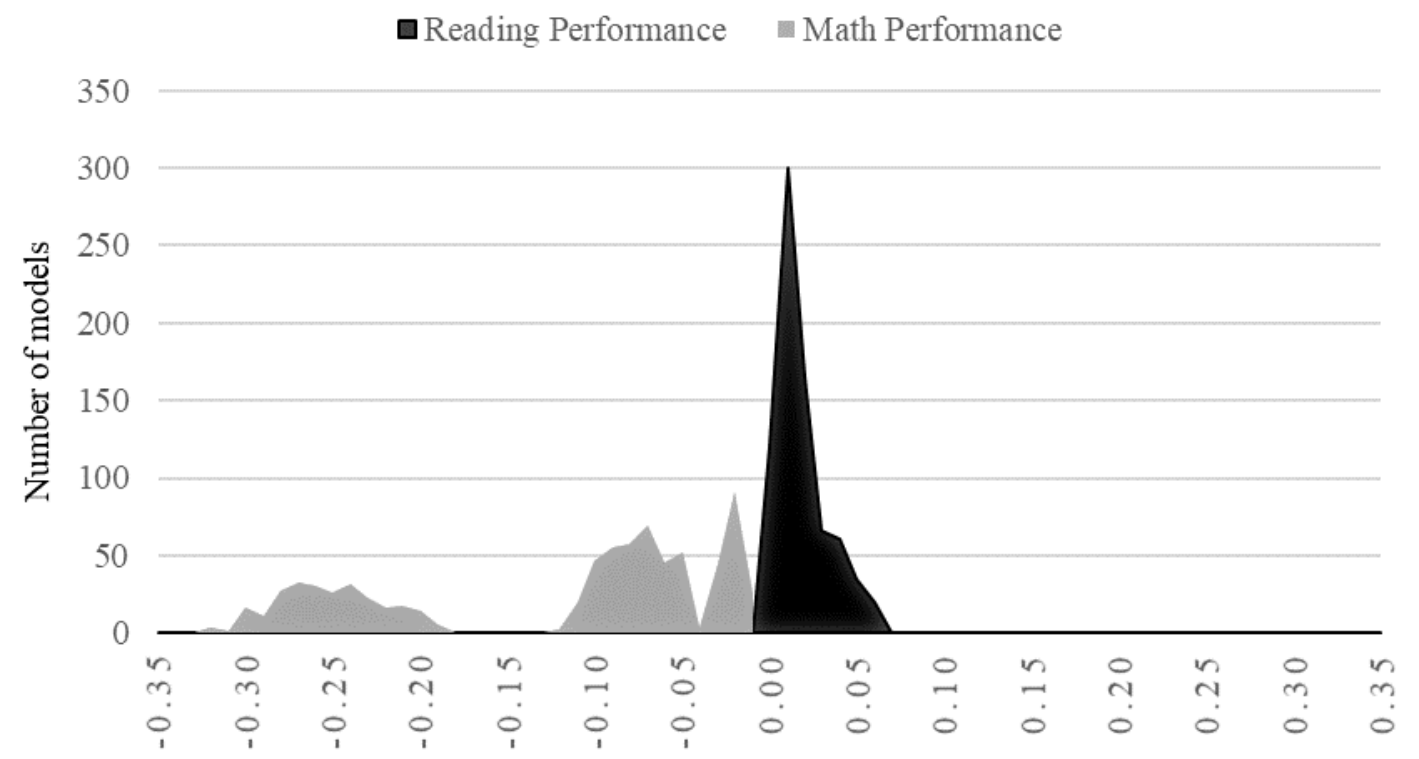

